IGNACIO DÍAZ DE LA SERNA

\title{
Poder y Paideia
}

$\mathbf{H}^{2}$ acia el siglo $\mathrm{V}$ a. de $\mathrm{C}$. aparece en Grecia una nueva sociedad urbana que busca derrocar a la clase aristocrática. Empresa nada fácil, pues esa sociedad emergente carecía de un sistema educativo. En contrapeso, el programa de la educación aristocrática era global, con él se pretendía desarrollar al máximo las facultades físicas e intelectuales de quienes un día ejercerían el poder. Por la amplitud de sus propósitos, resultaba muy superior a la educación profesional en la que de padres a hijos se transmitía la técnica de un oficio. Esto condujo a la necesidad de configurar un nuevo plan de educación destinado a satisfacer los ideales que el hombre de la polis perseguia.

A la par del nacimiento de esa sociedad urbana, se intenta llevar a cabo una arethé distinta a la arethé de la clase aristocrática. Todos los ciudadanos libres del estado ateniense son ahora considerados descendientes de la estirpe ática, miembros de la sociedad estatal y obligados a servir a la comunidad. Era imposible que la arethé política continuara dependiendo de lo que con anterioridad había sido la sangre noble, porque la admisión del pueblo en el estado, hecho que parecía más y más inminente, fue el modo de conformar a éste último.

Surge entonces un movimiento educador que cristaliza en la sofística. Por primera vez, ella extiende a todos los círculos y hace pública la exigencia de una arethé cimentada en el saber. Pese a que la comunidad había ya propuesto ampliar el horizonte de los ciudadanos mediante la educación de los individuos, posteriormente se pensó que para mantener estable un orden democrático era preciso acertar en la elección de aquellos que habrían de regir el estado.

El empeño que pusieron los sofistas en enseñar la arethé política fue la expresión inmediata del cambio radical operado en la estructura del estado. Su tarea educativa estaba alentada por una concepción distinta del hombre. Lo concibieron en una dimensión original, a la manera de un miembro activo partícipe 
de la comunidad. Irrumpe con ellos la idea del hombre como sujeto que puede realizarse tan sólo dentro de la polis, por lo que su programa educativo se vinculó con la esfera de los valores morales. La conocida sentencia atribuida a Protágoras nos indica la orientación que los sofistas asumieron al tratar el problema de la aletheia (no-encubrimiento) y su valor. En "el hombre es la medida de todas las cosas" subyacen dos consideraciones primordiales. La primera, que el no-encubrimiento constituye la auténtica labor de la [filosofía], esto es, importa desencubrir aquello que de costumbre es dado por supuesto. La segunda, afirma el valor relativo de la verdad. Ese valor correspondía a la concepción de un hombre-medida como individuo en su variable subjetiva momentánea.

Ante todo, la sofística fue un fenómeno pedagógico y social. A su lado, la retórica comprendía una parcela específica de la cultura. Así como Protágoras apenas se preocupaba por lo que no apuntara al aspecto cualitativo (el cómo) de las cosas, así Gorgias sostuvo que la grandeza del arte de la retórica radicaba en el hecho de elevar la fuerza oral a una instancia decisiva en el terreno más sobresaliente de la práctica humana: la política. Sin embargo, la reacción contra la educación impartida por los sofistas pronto se desencadenó, iniciándola Sócrates. Más tarde, Platón caracterizará -o mejor, ridiculizará- la esencia de esa techné, comentando que su representante Gorgias era incapaz de definirla. Cierto; el ejercicio de la retórica brindaba poder a la persona que conseguía dominarlo. Ambos, Sócrates y Platón, entendieron esta posibilidad como un defecto insalvable en la enseñanza de los sofistas.

¿Qué hubo detrás de este rechazo? Mencionemos algunas implicaciones. Desde sus inicios, el arte de la retórica se declaró indiferente a un tipo de problemas. Presuponía que la moral establecida por la sociedad era reductible a una simple cuestión convencional. De ahí la imposibilidad de conocer el valor universal de los valores morales. Todo el conocimiento debía circunscribirse, pues, a afirmar la relatividad de los opuestos entre sí y la identidad entre lo verdadero y lo falso (cfr. Eutidemo, 286). Además, los problemas inherentes a cualquier conducta regida según determinados principios morales -conocer y diferenciar lo bueno de lo malo, lo justo de lo injusto- no podían considerarse problemas reales. Por el contrario, la fuerza, la persuasión mediante la palabra, el derecho del más fuerte, fueron postulados como la moral más alta. Con semejante franqueza y honestidad admitía la retórica sus objetivos. 
Sin rodeos, Sócrates proclama que la retórica no es una verdadera techné. De hecho, su crítica irá elaborándose poco a poco a partir de esta consideración. No obstante, para lograr un mejor contraste de esa crítica, conviene que aclaremos antes el sentido original de este término. Entre los sofistas, la techné significaba una actividad práctica, no interesaba cuál, basada en ciertos conocimientos que requerían de especialización. Tal actividad práctica era la meta que los sofistas anhelaban alcanzar. En consecuencia, no es extraño que la techné política deseara a toda costa actuar sobre los fenómenos sociales que acontecían en la polis. Lejos de referirse a un conocimiento acerca de la naturaleza de las acciones o valores morales, era un conocimiento que procedía siempre de la actividad que lo originaba. Mucho más amplio, el significado de techné rebasaba al ámbito de lo. que hoy entendemos por "arte". Principalmente porque ella expresaba el valor práctico que la sabiduría poseía en la tarea de la educación.

Contrario a este sentido originario de la techné, Sócrates impone otro criterio que refutará la preponderancia del actuar. Dicho criterio exigía tres condiciones indispensables para que toda techné fuese verdadera. En primer lugar, todo conocimiento debía constituir un saber sobre la naturaleza de su objeto; segundo, le era forzoso conocer las razones por las cuales procedía; y por último, debía perfeccionar el objeto sobre el que se ejercitaba la práctica de ese conocimiento. Decididos, Sócrates y Platón contrapusieron la justicia verdadera a la retórica, ya que ésta no cumplía las condiciones anteriores. El conocimiento de la naturaleza y esencia de la justicia tenía que anteceder a la realización de cualquier acto justo. Estimaron, por ende, que la enseñanza política de los sofistas estaba irremediablemente condenada al fracaso. No sólo se las ingeniaron para invertir el criterio de verdad que los sofistas postulaban; por añadidura, concluyeron que si era factible distinguir el bien del mal, la justicia de la injusticia, como en efecto lo era, entonces la sofística confundía estos valores porque carecía de un saber exacto.

La inversión introducida por Sócrates -valorar el conocimiento abstracto de las esencias por encima del actuar- trajo consigo la negación del valor de la actividad práctica como la finalidad de toda techné. La actividad de la razón ocupó en lo sucesivo esa primacía. A la postre, su repudio de la retórica orilló a Sócrates a definir su propia postura ante el valor de un problema acuciante que concernía por igual a él y a los sofistas: el poder.

Al polemizar contra los sofistas, Sócrates ansiaba erradicar los valores que ellos defendían. Mas fue Platón quien, poco despúes, 
puso término a esa controversia, respaldado por un cuerpo sólido, sistemático, de proposiciones. La teoría del Estado platónico anunció con grande batahola el triunfo de un ideal cuya simiente había esparcido Sócrates. Incontrovertible, trátabase de una teoría fundamentada en el cuidado socrático del alma, cuidado que desempeñaba una función pedagógica, pero sobre todo, una función terapéutica. En fin de cuentas, lo que enseñaba Sócrates a sus discípulos era una teoría efectiva que preservara a los hombres del extravío de los nuevos valores supremos. Tal cuidado favorecía la educación moral de los futuros legisladores. Y para acometer esa tarea, el mejoramiento y la conservación del cuerpo y del alma, existían cuatro artes: la legislación, la justicia, la gimnasia y la medicina. Justamente ellas reemplazarian a las cuatro anteriores.

El programa educativo socrático-platónico fue el fruto de aquel afán por establecer un orden diferente en el estado. Los sofistas ofrecían todo menos los fundamentos para consolidar una estructura social perdurable, armónica, segura. Invirtiendo la finalidad del conocimiento, transformaría la concepción de la sociedad hasta entonces imperante. Sócrates no tardó en hallar la fórmula infalible que aseguraría el éxito de ese cambio. Había que cambiar el modo de valoración.

El Gorgias de Platón nos relata el enfrentamiento entre Sócrates y el sofista Calicles. Se desarrolla el diálogo, Calicles cae en la cuenta de lo que ambiciona su oponente, y repudia sin ambages la inversión socrática de los valores (cfr. Gorgias, 481c). Mientras que Sócrates no entiende por qué la retórica ejerce tanta influencia en la vida política de Atenas, los sofistas, a su vez, comprendieron desde el principio que la aspiración al poder era un fenómeno arraigado en la naturaleza humana. Encubrirlo era asunto difícil. No contentos con entender ese fenómeno, aspiraron a la práctica real del poder. Sabían que la retórica sí constituía una verdadera techné en la medida en que aceptaba abiertamente que su objetivo se desprendía de la naturaleza misma. Por lo demás, ella se interesaba también en reflexionar sobre los medios necesarios para hacerse del poder.

En la disputa de Sócrates con los sofistas, debatían en realidad dos concepciones irreconciliables del mundo y de la naturaleza humanos. El nuevo humanismo socrático-platónico se alzó contra el humanismo de los sofistas, quienes estaban a favor de una naturaleza del hombre jaloneada por los instintos. Socrátes y Platón, por su parte, preconizaron la racionalidad absoluta de los actos. Dio comienzo así la lucha entre el poder y la paideia. Ya lo 
señaló atinadamente $\mathrm{W}$. Jaeger. ${ }^{1}$ Con el humanismo socráticoplatónico aparece la primera gran disyunción de nuestra historia. Una cultura de súbito lanzada a su suerte, obligada a optar por una filosofía del poder o una filosofía de la educación.

Como paso inicial en el desarrollo de su concepto de paideia, Platón enfrentó el espíritu al poder, la frónesis a la dynamis. No ignoraba que la dynamis conducía al poder que controlaba al estado. Desdeñando el poderío físico, rechazo una filosofía del poder sustentada en la violencia. La paideia platónica se dispuso, por tanto, a ensayar otras vías. La más importante de cuantas recorrió fue proponer otra finalidad de la vida a los hombres de su tiempo: cada cual habría de esforzarse en alcanzar la perfección conforme al destino de su propia naturaleza. Desde su fundamento, se mostró adversa a la injusticia, a la maldad. Esa actitud explica su carácter esencialmente ético.

Adelantándose, Śćcrates había vislumbrado ya el derrotero que debía seguir esta nueva paideia. En su opinión, la sofística tenía poco o nada que decir acerca del conocimiento y de los valores morales. Ambos temas necesitaban ser abordados con otra óptica; decidió entonces elevar la dialéctica a la forma suprema de conocimiento. En tanto que la retórica hacía caso omiso del pensar, la dialéctica se convirtió rápidamente en el único camino posible hacia el conocimiento objetivo. Sólo ella estaba en condiciones de proporcionar una concepción estable de la vida humana. Más aún, el menosprecio de la retórica lo justificaba de sobra su completa falta de rigor lógico. Socrátes no dudó en rebelarse ante la sabiduría práctica de los sofistas, convencido de que urgía frenar esa "naturaleza anormal" de conocimiento, puesto que la sabiduría proveniente de los instintos representaba un serio obstáculo para llegar al conocimiento consciente. La conciencia fue proclamada de inmediato el principio de toda fuerza creadora. En el futuro, el pensamiento filosofico se desenvolvería sobre su nuevo fundamento: la racionalidad.

De este cambio resultó un nuevo modo de existencia promovido por el hombre teórico. Dando origen a una manera distinta de comprender los fenómenos naturales, el conocimiento racional sostuvo que existía una relación de necesidad entre causa y efecto. La idea se difundió, tornándose fructífera en la ética. La misma relación causal bien podría ocurrir entre la culpa y 
el castigo, entre la virtud y la felicidad. El empleo de la dialéctica condujo a negar como verdadero aquello que no fuese aprehensible conceptualmente. Para colmo, se creyó que el pensamiento era capaz de rastrear una $u$ otra secuencia causal hasta adentrarse en los sorprendentes pozos del ser (cfr. Timeo,V 28).

Pero regresemos un segundo al tema que antes nos ocupaba: la reacción de Calicles frente a la perspectiva socrática del conocimiento. Es verdad que Calicles veía, no sin admiración, que el rigor lógico de la dialéctica se manifestaba a través de la actitud de Sócrates. Una actitud coherente, bien defendida. En suma, él era el individuo que exhibía en Atenas los logros asequibles mediante una vida apegada a la racionalidad. Sin embargo, veía también que el rigor de la fortaleza socrática se desmoronaba en añicos cuando se trataba de encarar las experiencias de la realidad. En efecto, Sócrates acabó siendo condenado a muerte. Y su condena no obedeció a que hubiese negado la existencia de los dioses o corrompido a la juventud ateniense. El motivo de ese dictamen permanece muchas veces oculto. Semejante condena fue la respuesta de los estadistas y ciudadanos cuando percibieron el peligro inminente que constituía la tendencia hacia una cultura superior del espirítu más allá de la realidad.

Calicles no sólo desenmascara la dirección a la que apunta la enseñanza de Sócrates. Pone asimismo en evidencia los subterfugios que éste ha utilizado para establecer un criterio diferente de verdad. No acepta que el poder sea la finalidad del hombre, como sería el caso de Gorgias, sino que se esfuerza en dar con una explicación más satisfactoria de la tendencia al poder, derivándola de la naturaleza misma. Esto lo llevó a hacer la distinción entre lo que era justo de manera convencional conforme a la ley (nomos), y lo que era justo conforme a la naturaleza. Encontró, además, que para Sócrates no había tal diferencia, lo que le permitía confundir a sus interlocutores. Si ellos no la distinguían, tampoco lo hacía Sócrates.

Con Calicles empezamos a dilucidar el verdadero sentido de la nueva paideia, el sentido de una cultura que emerge contraria a la fortaleza fisica natural. Para él, la capacidad de autodefensa que muestra cada individuo representa el único criterio del hombre auténtico y una justificación ética de la tendencia al poder. Algunos viven la resignación ante la violencia recibida; otros emplean su fuerza y consiguen imponerse. Frente a esta situación de desigualdad, la ley genera un artificio que limita o suprime la utilización de esa fuerza. Las leyes del estado y de la moral intimidan la espontaneidad de los individuos; son creadas 
para hacer valer el ideal de igualdad. La limitación de la fortaleza física, de la capacidad de autodefensa, va apuntalándose a través de una cultura y una domesticación que tienen por ideales los ideales de aquellos que sufren la desigualdad y la injusticia. Luego, un derecho legal por convención se opone al derecho por naturaleza, el cual delinea los contornos de una nueva sociedad regida por los ideales de la nueva paideia.

Finalmente, Calicles ha descubierto que el sentido de la nueva cultura es la domesticación de las naturalezas fuertes. Ella será un sistema de valores, fundado en el engaño, que no codicia sino la ascensión al poder. El intento por lograrlo se hace patente con claridad en el concepto que Platón formula de la paideia: una labor que debe abarcar la totalidad de la vida humana. Abarcar dicha totalidad significa no descuidar ningún resquicio por donde el mal de la antigua cultura pueda entrometerse. Platón lo ignora, pero en ese momento se ha convertido en aquel caballero de la virtud que lucha denodadamente contra el mundo, proponiendo una expresión ascética de la vida y una valoración positiva de la muerte. Una valoración que corresponde al anhelo de un mundo ideal en el que sea factible recuperar lo perdido o acaso lo que nunca pudo conseguirse; un ascetismo que corresponde a la situación real del individuo que ha padecido en carne propia la injusticia.

Al tiempo que Sócrates repudia la filosofía del poder y del derecho natural, implanta otro modo de existir: la vida filosófica, la vida del hombre pensante. Sólo en ella se adquiere un conocimiento verdadero de la esencia del hombre y de su finalidad. El bien y la justicia son su objetivo. Este conocimiento fue - ya se mencionó - una terapia tanto individual como colectiva.

En su interés por obtener un conocimiento racional, absoluto, Socrátes y Platón llevaron adelante una nueva valoración de la existencia. Con ayuda de un novedoso programa educativo, opuesto al de los sofistas, sentaron las bases de lo que debía ser la vida de los hombres. Los nuevos valores que difundieron fueron la justicia, la moderación de los instintos y de las pasiones, la prudencia, la virtud y el ascetismo. Por otro lado, la eternidad, la universalidad, la inmutabilidad, fueron las características más destacadas de esos valores. Un buen ejemplo lo tenemos en la crítica que Platón elabora de la poesía y del lenguaje en general. ${ }^{2}$

2 La palabra y el lenguaje reflejan la movilidad de lo sensible. Por tanto, no pueden ser un conocimiento veradero, tal como lo serian los conceptos. Cfr. Teetetos, XXVIII, 183. 
Platón arguye que la poesía no es fuente de educación porque busca, al igual que la retórica, el reconocimiento del pueblo y no la consecución del Bien. El término póiesis, del cual proviene "poesía", tuvo originariamente el significado de la acción que hace. Póiesis equivale a invención; transformación del mundo real en un mundo cualitativamente transfigurado. La acción que hace, que transforma, siempre se renueva. Por esta cualidad, al despreciar Platón la poesía como una forma de paideia, despreció también la naturaleza de la palabra. Su rechazo de la poesía presupuso la negación de toda capacidad generativa. Platón se dedicaría a organizar su doctrina enfrentando el concepto a la palabra, la representación a la invención, el pensar al actuar.

La supremacía del pensar sobre el actuar, del conocimiento por definición del juicio valorativo sobre el acto moral, se manifiesta en la misión que Platón asigna a los estadistas. El gobernante debe conocer y proceder siempre a partir de un eidos lo más perfecto posible, con lo cual le será más sencillo orientar su actividad correctamente, ordenando las partes del todo (estado) en función del bien común. Por consiguiente, el estadista, para ser justo, ha de poseer el conocimiento universal del valor justicia. Unicamente así podrá ejecutar sus actos de tal manera que estén dirigidos al orden del reino espiritual.

Platón concluye que el problema de toda la paideia estriba en el conocimiento de los valores universales, de la norma suprema a la que la acción humana debe ajustarse. La finalidad última de este conocimiento es el valor supremo del Bien. El camino hacia la plena felicidad es el camino de la arethé humana. A su vez, la meta de la vida de los hombres será la consecución de esta excelencia mediante el obrar bien. ${ }^{3}$ La seguridad que proporciona este tipo de conocimiento no se reduce a proteger a los individuos de sufrir la injusticia; los protege de cometerla. ${ }^{4} Y$ esto dependerá, seguin Platón, del cumplimiento cabal de la nueva paideia.

En la medida en que la nueva paideia aspiró a conocer la finalidad última del hombre, el Bien fue postulado principio ontológico de la realidad (cfr. República, VI, 19, 508). ${ }^{5}$ Los dos pun-

3 El obrar bien significa la realización del ergon propio. Véase Guthrie, Los Filosofos Griegos, FCE, pp. 110-11.

4 Para Platón, es preferible recibir una injusticia a cometerla, punto de vista que ejercerá posteriormente una gran influencia en Aristóteles, cfr. Ética a Nicómaco, VI, 13, 1145.

5 Para un análisis más detallado, véase Raphael Demos, "Plato's Idea of the Good", en The Philosophical Review, No. 46, 1953. 
tos que Platón argumenta en defensa de esta ontología son: a) que el Bien es la causa absoluta y principio de toda la secuencia causal que constituye el mundo de los fenómenos; b) que la existencia de la naturaleza se origina en la existencia del Bien, esto es, ofrece una respuesta a la pregunta por qué el mundo existe. La ontología de Platón vendrá a justificar al Estado ideal como la condición necesaria para que se logre cumplir el Bien supremo. Al parecer, ni Sócrates ni Platón intentaron reformar la paideia existente, porque estuvieron de acuerdo en que era el estado el que requería ser transformado desde sus raíces más hondas. Y para ello propusieron la nueva paideia. Más aquí se completa un círculo vicioso. Por una parte, el estado es el único que puede encargarse de esa tarea educativa; por otra , sólo a través de la nueva paideia se puede modificar el estado imperante. La solución que Platón halló para resolver esta necesidad recíproca consistió en idear un Estado arquetípico; necesidad que desembocó en un boceto teórico del Estado contrapuesto al Estado real jurídico, social y político.

De este modo se eslabonan las dos nociones medulares del pensamiento platónico: el Estado y la paideia. Mientras que los sofistas discutían en torno al valor de las diversas formas de gobierno, Platón, distanciándose de ellos, mantendrá que es indispensable abordar ese problema a partir de la justicia, tomando en consideración su naturaleza y valor universales. Elorigen del concepto de lo justo radica en el alma. Si el ideal de justicia es fundamento del Estado platónico, el alma humana reproduce entonces el prototipo de ese Estado. En la Repríblica, por ejemplo, el tema del Estado sirve como medio para llegar a un fin específico: fijar la esencia y la función de la justicia en el alma. El principio del Estado ideal se encuentra a su vez relacionado con la arethé o excelencia que cada individuo alcanza al llevar a cabo su propio ergon en armonía con el todo. Platón hace hincapié, además, en que la parte racional del alma debe dominar sobre las restantes (cfr. Fedro, XXV-VI, 246 y 253). Sin embargo, la intención de este paralelismo Estado-alma se descubre cuando Platón juzga a los filósofos con legítimo derecho a detentar el poder dentro del Estado (cfr. Repriblica, VI, 484-85).

Cabe preguntarse, pues, si fueron el Bien, la justicia, la felicidad, los fines que persiguió la nueva paideia. Parecería que no. Ella fue, de hecho, un programa educativo encaminado a la adquisición del poder, procurando que el filósofo - prototipo del hombre justo- se adueñara de él. Junto al nuevo orden social, habrían de consolidarse los valores de la nueva cultura que tenía 
por sujeto al hombre pensante. Atrás iría quedando lamentablemente una época en la que otros hombres, aquellos cuyas hazañas y pasiones desmedidas contó Homero, héroes histriónicos entregados al honor de la guerra, se complacían en ser los bufones celestiales. 